\title{
Effectiveness of Ilmetin against neonatal diarrhea of piglets
}

\author{
Anatoly I. Trubkin ${ }^{1 *}$, Minsagit H. Lutfullin ${ }^{1}$, Danil N. Mingaleev ${ }^{1}$ and Marina A. Efimova ${ }^{1,2,3,4}$ \\ ${ }^{1}$ Kazan State Academy of Veterinary Medicine named after N.E. Bauman, Kazan, 420029, Russia \\ ${ }^{2}$ Kazan Federal University, Kazan, 420008, Russia \\ ${ }^{3}$ Federal Center for Toxicological, Radiation and Biological Safety, Kazan, 420075, Russia \\ ${ }^{4}$ Russian Medical Academy of Continuous Professional Education of the Ministry of Healthcare of the Russian Federation, Kazan, \\ 420012, Russia
}

\begin{abstract}
The aim of the present work was to study the effectiveness of Ilmetin and the method of its use in neonatal diarrhea of piglets. The drug Ilmetin (patent for the invention No. 2542466) was developed at the Department of Epizootology and Parasitology, Kazan State Academy of Veterinary Medicine named after N.E. Bauman. A new herbal preparation was obtained by sublimation from elm bark, which contains tannins, flavonoids and other active substances. The influence of Ilmetin on hematological parameters, growth and development of piglets with neonatal diarrhea in a production environment was studied. The use of the Ilmetin preparation for the treatment of acute gastroenteritis of piglets contributed to an easier course of the disease, a quick healing process and ensured $100 \%$ preservation of suckling piglets in comparison with the generally accepted treatment regimen for acute piglet gastroenteritis.
\end{abstract}

\section{Introduction}

The cultivation of young animals who are healthy, welldeveloped and adapted to the conditions of intensive technology of keeping is the basis of effective livestock breeding. One of the main problems of animal husbandry in our country is young diseases, among which the main percentage is gastrointestinal diseases, causing significant damage to the national economy. Of the variety of diseases characteristic of colostrum calves, dyspepsia is the most common disease [1].

In practice, antimicrobials are mainly used as etiotropic therapy, but their long-term administration is often accompanied by rapid development of fungi, staphylococci, hemolytic strains of Escherichia coli and Proteus [2, 3].

It is known that the irrational use of etiotropic antimicrobial drugs in calves' dyspepsia leads to severe complications and the occurrence of dysbiosis. As a result of this, digestion and metabolism are disrupted, and the gain in live body weight is reduced. $[4,5]$.

According to the WHO, the main consumer of antibiotics is agriculture, which in turn leads to the emergence of antibiotic-resistant strains of microorganisms that are dangerous for both animals and humans. Around the world, work is underway to reduce the use of antibiotics, as the European Union introduced a ban on the use of feed antibiotics since 2006 .

Tissue preparations, which stimulate the compensatory mechanisms and metabolic processes in the body, are widely used in veterinary medicine, which is provided by the biologically active substances that make up their composition - these are enzymes, hormones, amino acids, vitamins, and low molecular weight peptides [6]. However, these drugs, along with the desired targeted effect on various aspects of the functional activity and productivity of animals, under certain conditions can also have a negative side effect.

The arsenal of tools used in the treatment of dyspepsia is currently quite large. At the same time, in the majority these are expensive drugs, inaccessible in the conditions of a modern economy and not always effective.

Recently, scientists in many countries have been proposing, as an alternative to chemotherapeutic antimicrobial drugs, herbal remedies. An important advantage is that, unlike feed antibiotics, herbal preparations can be used throughout the entire production cycle.

The use of herbal preparations does not cause damage to other organs and systems, on the contrary, it contributes to the general strengthening effect of biologically active substances of plant origin on the body of dairy pigs and, as a result, increases the gain in live weight and ensures a reduction in the adaptation period. In this regard, the development, study and implementation in veterinary practice of therapeutic and prophylactic preparations of plant origin is an urgent task [7, 8].

The aim of our research was to study the effect of Ilmetin on hematological parameters, growth and development of piglets with patients with neonatal diarrhea.

*Corresponding author: anatoliy_trubkin@mail.ru 


\section{Materials and Methods}

We used the drug Ilmetin, developed at the Department of Epizootology and Parasitology of the Kazan State Academy of Veterinary Medicine named after N.E. Bauman, Doctor of Veterinary Sciences, Professor M.V. Kharitonov (patent for invention RU 2542466). The studies were carried out at the Department of Epizootology and Parasitology Kazan State Academy of Veterinary Medicine and in the conditions of the farm of the Republic Mari El.

The preparation of the drug was carried out in a laboratory meeting the requirements of GOST R 525372006 Production of medicines. Quality Assurance System. General requirements.

The determination of the sterility drug Ilmetin was carried out in accordance with GOST 28085-2013, by seeding on MPA, MPB, medium Kitt-Tarozzi and Saburo-agar.

The experiments were carried out on 20 pigs of daily age, of Large White breed. Animals were divided into experimental and control groups of 10 animals each. In piglets of the control and experimental groups at the beginning and during the experiment, feces were taken for coprological studies.

The studies were carried out according to the educational-methodical manual [9]. Feces were taken in clean, dry containers after defecation. The following indicators were studied: shape, color, texture, occult blood, fat and fatty acid content, mucus, the presence of leukocytes, erythrocytes, epithelium, helminth eggs, protozoa pathogens, the ratio of rod-shaped and coccal forms of bacteria.

In addition to the iron-containing preparation, piglets of the experimental group were additionally prescribed Ilmetin for 3, 10, and 15 days. The drug was administered intraperitoneally at a dose of $3 \mathrm{ml}$, and piglets of the control group were treated according to the treatment regimen used in the farm.

Weighing of control and experimental animals was carried out in the period from 1 to 31 days of life, ekly.
Based on the weighing results, the average daily gain in body weight was also calculated. Blood for research from piglets was taken from the tail vein for 1 and 30 days. The following indicators were determined in whole blood: the content of hemoglobin, red blood cells, and white blood cells according to generally accepted methods.

Biometric processing of the research results was carried out using a computer in Microsoft Excel using the methods of variation statistics. The arithmetic means of each variational series, standard errors of the mean, the degree of probability of the null hypothesis in comparison with the control are determined by calculating the Student-Fisher criterion. At $p<0.05$, the difference in the arithmetic mean of the compared variation series was considered significant.

Animal experiments were conducted in strict compliance with the requirements on the use and wellbeing of experimental animals (the rulesof the Russian Federation Ministry of Agriculture as well as internationalregulations) and were approved by the Local Ethics Committee of the Kazan State Academy of Veterinary Medicine named after N.E. Bauman.

\section{Results}

The clinical picture of the disease of piglets before the start of the experiments in both groups was almost the same. Piglets were depressed, sometimes a convulsive contraction of certain muscle groups was observed. General weakness, anorexia, thirst, dryness of the mucous membranes and skin were expressed.

The sides and abdomen were tightened, the back was hunched over, the skin of the pelvic limbs and hips was stained with feces. Sick piglets often lay and reluctantly got up. Intestinal motility and the act of defecation in sick piglets were more frequent.

The excreted faeces had the appearance of a liquid and gruel-like consistency, yellow and white, with a fetid odor. The physiological parameters of the piglets selected for research are presented in Table 1.

Table 1. The main physiological indicators of piglets before the experiment

\begin{tabular}{|l|c|c|}
\hline \multicolumn{1}{|c|}{ Indicators } & Experienced group & Control group \\
\hline Temperature, $\mathrm{C}^{0}$ & $39.19 \pm 0.21$ & $39.09 \pm 0.28$ \\
\hline Pulse, beats / min & $222.70 \pm 0.77$ & $219.50 \pm 0.48$ \\
\hline Respiration in 1 min & $83.80 \pm 0.58$ & $82.80 \pm 0.47$ \\
\hline Bowel frequency, once a day, \% & 0 & 0 \\
\hline - normal & $58.62 \pm 1.73$ & $57.62 \pm 1.20$ \\
\hline - over 10 times & $14.39 \pm 0.26$ & $13.99 \pm 0.22$ \\
\hline - 5-7 time & $13.12 \pm 0.14$ & $13.10 \pm 0.14$ \\
\hline - 2-3 time &
\end{tabular}

Coprological studies of fecal samples of experimental piglets exclude the role of helminths in the etiology of acute gastroenteritis. Starting from the 14th day of treatment with Ilmetin, the state of the piglets in the experimental group improved significantly. Piglets actively reacted to external stimuli; food excitability was restored.
The frequency of bowel movements became normal: 1-2 times a day in the morning and evening. The condition of the piglets in the control group differed markedly from the experimental one at the end of the experiment. In the remaining piglets of the control group, by the end of the experiment, the appetite improved and the activity of the animals increased, but the diarrhea in individual piglets persisted, the feces were creamy 
consistency. The physiological indicators of piglets after the experiment in the control group significantly differed from the indicators of the experimental group (Table 2).

Table 2. The main physiological indicators of piglets before the experiment after completing the experiment

\begin{tabular}{|l|c|c|}
\hline \multicolumn{1}{|c|}{ Indicators } & Experienced group & Control group \\
\hline Temperature, $\mathrm{C}^{0}$ & $38.7 \pm 0.06$ & $41.0 \pm 0.13$ \\
\hline Pulse, beats / min & $22.0 \pm 3.00$ & $242 \pm 4.43$ \\
\hline Respiration in 1 min & $82.0 \pm 0.64$ & $98 \pm 2.86$ \\
\hline Bowel frequency, once a day, \% & \multicolumn{2}{|}{} \\
\hline - normal & $96.88 \pm 0.37$ & $20.53 \pm 0.22$ \\
\hline - over 10 times & 0 & $43.95 \pm 0.17$ \\
\hline - 5-7 time & $3.12 \pm 0.29$ & $20.40 \pm 0.11$ \\
\hline - 2-3 time & $10.46 \pm 0.11$ & $15.19 \pm 0.20$ \\
\hline
\end{tabular}

Microscopic examination of feces at the end of the experiments revealed insufficient digestibility in sick animals (control group) due to the rapid passage of feces through the gastrointestinal tract. In animals of the experimental group, the digesting ability increased, since the amount of detritus increased as a result of the use of the Ilmetin preparation. Detritus is the main background in normal stool microscopy. The more complete the digestion, the greater the detritus in the feces [10].

According to literature data [11], it is known that an increase in the number of leukocytes in the feces indicates an inflammatory process. In the feces of healthy animals, single leukocytes can be detected. In our experience, in the group of animals to which the

Ilmetin preparation was administered, leukocytes were not detected. Microbiological studies established the ratio of rods and coccal flora in samples of feces: in animals of the control group it was $85 \%$ and $15 \%$, in the experimental group against the background of the use of the drug - 20 and $80 \%$, respectively. Analysis of the data showed that a pronounced imbalance in the ratio of rods and coccal forms of bacteria in feces in sick animals is normalized after the use of the Ilmetin preparation.

In a biological sense, growth as a process of increasing the total mass of cells of an organism, its tissues and organs over time is determined on the basis of data on the live weight of experimental animals (Table 3).

Table 3. Dynamics of live mass of pine piglets, $\mathrm{kg}$

\begin{tabular}{|c|c|c|c|c|c|}
\hline \multirow{2}{*}{ Group } & \multicolumn{5}{|c|}{ Age, days } \\
\cline { 2 - 6 } & 1 & 7 & 14 & 23 & 31 \\
\hline Control & $1.46 \pm 0.06$ & $2.45 \pm 0.11$ & $3.25 \pm 0.30$ & $5.86 \pm 0.41$ & $6.73 \pm 0.41$ \\
\hline Experimental & $1.45 \pm 0.05$ & $2.38 \pm 0.22$ & $3.44 \pm 0.32^{* *}$ & $6.30 \pm 0.26^{* *}$ & $7.07 \pm 0.27^{* *}$ \\
\hline
\end{tabular}

Note: $* * \mathrm{p}<0.01$ compared to the monitoring group

Table 3 presents the changes in body mass indicators, the experimental groups will be asked - suckers in the period from 1 to 31 days of life.

From table 3 it is seen that when the experimental groups were formed, the average live weight for all groups was $1.45 \mathrm{~kg}$. The greatest live weight was observed in the experimental group, where the drug Ilmetin was intraperitoneally administered to piglets on the 3rd, 10th and 15th day. A noticeable difference in live weight in the experimental group was noted starting from two weeks of age. By the age of one month, the piglets of the experimental group surpassed the control group by $340 \mathrm{~g}$.

In animals, appetite improved, neuromuscular tone increased, visible mucous membranes acquired a natural pink color. On the 30th day of the study, all piglets had a full recovery.

In the control group, 4 suckling piglets recorded an upset gastrointestinal tract accompanied by watery bowel movements with a specific odor. Sick piglets were given antibiotic therapy. During treatment, 2 pigs with a diagnosis of gastroenteritis fell in the control group. The safety of piglets in this group was $80 \%$.
Morphological and biochemical blood tests make it possible to objectively assess the physiological state of the animal organism.

The results of hematological studies are presented in Table 4.

Along with hematological parameters, when studying the general condition of a sick animal, the biochemical parameters of blood serum are of great importance. The results of biochemical studies showed a significant decrease in total protein $(19 \%)$, reserve alkalinity $(9.5 \%)$, and carotene (40\%), which are of great importance in the functional activity of the whole organism. It follows that the sooner we eliminate these disorders, the better for the body as a whole.

According to the results of hematological studies, it was found that Ilmetin, when applied to suckling pigs, has a positive effect, accompanied by an increase in their number of red blood cells by $10.5 \%$ and platelets by $10.3 \%$ compared with animals in the control group. The hematocrit in animals of the experimental group increased by $9.35 \%$ compared with the control and amounted to $36.24 \%$; this testified to the cessation of the dehydration of the calves. 
Table 4. Hematological indices of pine piglets using «llmetin»

\begin{tabular}{|c|c|c|c|c|}
\hline \multirow{2}{*}{ Group } & \multicolumn{5}{|c|}{ Показатель } \\
\cline { 2 - 5 } & Erythrocytes, $\mathrm{x} 10^{12} / 1$ & Leucocytes, $\mathrm{x} 10^{9} / 1$ & Platelets, $10^{9} / 1$ & Hemoglobin, $\mathrm{g} / \mathrm{l}$ \\
\cline { 2 - 5 } & \multicolumn{4}{|c|}{ background } \\
\hline Control $(\mathrm{n}=10)$ & $5.10 \pm 0.26$ & $7.02 \pm 0.91$ & $349.1 \pm 13.8$ & $84.5 \pm 0.76$ \\
\hline Experimental $(\mathrm{n}=10)$ & $5.14 \pm 0.22$ & $6.89 \pm 0.76$ & $275.2 \pm 24.0$ & $84.6 \pm 0.79$ \\
\hline \multicolumn{5}{|c|}{ for the 30th day } \\
\hline Control $(\mathrm{n}=8)$ & $6.25 \pm 0.37$ & $12.33 \pm 1.29$ & $412.3 \pm 19.8$ & $96.6 \pm 2.41$ \\
\hline Experimental $(\mathrm{n}=10)$ & $6.70 \pm 0.21^{* *}$ & $10.1 \pm 1.2$ & $313 \pm 30.3$ & $108.7 \pm 1.74^{* *}$ \\
\hline
\end{tabular}

Note: $* * \mathrm{P}<0.05$ compared to control group

Proteins in the animal's body perform many functions: they maintain the constancy of blood, take part in blood coagulation processes, are part of hormones, enzymes, and take part in immune processes. In animals of the experimental group there was an increase in the content of total protein in blood serum by $13 \%$ compared with the control group.

With an increase in total protein, there was an increase in globulins $-17.3 \%$. The percentage of $\gamma$ globulins is an indicator of protein fractions of blood serum, especially determining the immunological status of the animal organism (immunoglobulins).

The phagocytic activity of leukocytes increased to $45.6 \%$ in the control and to $49.4 \%$ in the experimental group. The content of erythrocytes and the hemoglobin level in piglets of the control group was lower than in the piglets of the experimental group, while the number of leukocytes remained above normal by the end of the study.

\section{Conclusion}

In previous studies on laboratory animals, we found that the drug Ilmetin has astringent, anti-inflammatory, bactericidal and bacteriostatic properties [12].

The use of the Ilmetin preparation in the production environment for the treatment of acute gastroenteritis of piglets contributed to an easier course of the disease, a quick healing process and ensured $100 \%$ preservation of the suckling piglets. Their mass at the time of weaning was $4.2 \%$ higher in comparison with the control.

The therapeutic effect of the test drug in the treatment of sick animals with functional disorders of the intestinal tract is likely due to the presence of tannins in its composition.

It is known that tannins protect the receptor apparatus of the mucous membranes of the digestive tract from irritation. This leads to a decrease in the secretory activity of the endocrine glands, a sharp decrease in the release of fluid into the lumen of the gastrointestinal tract and intestinal motility.

Due to the narrowing of blood vessels under the influence of tanides and especially that of the capillary network, the absorption of toxic products from the intestines into the body decreases, which eases the course of the disease and reduces the time of recovery of patients after treatment.

Thus, studies conducted in laboratory conditions and farms that have long been dysfunctional in gastrointestinal diseases of young farm animals, studies confirm the high therapeutic efficacy of the drug with a single intraperitoneal administration, it does not have an embryotoxic, teratogenic effect and is environmentally safe.

This study was supported by the Russian Government Program of Competitive Growth of the Kazan State Academy of Veterinary Medicine named after N.E. Bauman.

This research received no specific grant from any funding agency in public, commercial, or non-for-profit sectors.

\section{References}

1. G.R. Gandhi, P.G. Barreto, B.D. Lima et al., Phytomedicine, 15(23(14)), 1830-1842 (2016)

2. A.N. Panin, N.I. Grey, Veterinary medicine, 5, 1213 (1996)

3. E.A. Solovieva, T.V. Efremova, Vet. Pharma, 4 (2012)

4. V.V. Subbotin, M.A. Sidorov, Veter. Sci., 1, 3-6 (2004)

5. V.G. Papatsiros, E.D. Tzika, D.S. Papaioannou et al., Pol. J. Vet. Sci., 12(3), 407-414 (2009)

6. M.M. Alfajaro, H.J. Kim, J.G. Park et al., Virol J., 18(9), 310 (2012)

7. M.M. Alfajaro, M.C. Rho, H.J. Kim et al., Res. Vet. Sci., 96(3), 567-75 (2014)

8. A.I. Trubkin, M.V. Kharitonov, Sci. notes of the Kazan State Acad. of Veter. Med. named after N.E. Bauman, 231(III), 140-144 (2017)

9. M.H. Lutfullin, A.H. Volkov et al., Educational and methodical manual (Kazan, 2010), 38 p.

10. G.R. Gandhi, P.G. Barreto, B.D. Lima et al., Phytomed., 15(23(14)), 1830-1842 (2016)

11. J.H. Cho, S. Zhang, I.H. Kim, Asian-Australas J. Anim. Sci., 25(11), 1595-1604 (2012)

12. M.V. Haritonov, G.F. Kabirov, I.I. Idiyatov, Patent for the invention, RUS 2542466 (2012) 